ISSN: $1130-3743$

\title{
EDUCACIÓN Y CRISIS DEL SUJETO
}

\author{
Education and crisis of the self
}

Fernando GIL CANTERO

Universidad Complutense. Facultad de Educación. Centro de Formación del

Profesorado. Departamento de Teoría e Historia de la Educación. C/. Rector Royo

Villanova, s/n. 28040 Ciudad Universitaria. Madrid.gcantero@edu.ucm.es

Fecha de aceptación definitiva: marzo de 2002

BIBLID [(1130-3743) 13, 2001, 45-68]

\section{RESUMEN}

En este artículo se analizan las implicaciones educativas de la crisis de la idea de sujeto en el pensamiento contemporáneo actual. Se exponen las principales ideas en torno a la crisis de la idea de sujeto desde la filosofía de la razón, la filosofía del lenguaje y la filosofía de la moral. El autor detalla algunas de las implicaciones educativas más importantes: la sobrevaloración de la razón en los alumnos, desde un enfoque constructivista; la disminución del aprendizaje acumulativo de información; la excesiva utilización de los discursos educativos frente al valor formativo de las acciones; la confusión actual en el concepto de educación; la excesiva importancia dada a la educación informal; la identificación de la educación con la vida, etc. El artículo termina proponiendo la necesidad de elaborar una pedagogía de la resistencia creativa capaz de hacer frente a la crisis de la idea de sujeto.

Palabras clave: crisis, sujeto, posmodernidad, metas educativas, Teoría de la Educación.

\section{SUMMARY}

The paper analyses the educative implications of the crisis of the self in the current philosophy. The author revises the most important theories about the crisis 
of the self from the philosophy of the reason, the philosophy of the language and the philosophy of the moral points of view. The author note some of the more important educative implications: the overvaluation of the reason in the students from a constructivist approach; the decrease of the cumulative learning of information; the excessive use of the educative discourses in front of the formative value of the actions; the present confusion about the concept of education; the extreme value given to the informal education; the confusion between the education and life, etc. The paper ends proposing the necessity to do a pedagogy of the creative resistance to make possible confront the crisis of the subject.

Key words: crisis, self, postmodernity, educational claims, Theory of Education.

\section{LA CRISIS DEL SUJETO ${ }^{1}$}

Con este título se expresa, probablemente, una de las ideas filosóficas más recurrente de los últimos años. Aunque este tema tiene sus implicaciones educativas y, probablemente, sus causas en los diferentes modos en que los sujetos se relacionan con los demás y con la cultura, a nosotros lo que nos interesa precisar en este momento no es esta última cuestión (Asensio, Bárcena y Mèlich, 2001; Trilla, Ayuste, Romañá y Salinas, 2001; Salinas, 1998) sino algo más modesto, si bien, según entendemos, de mayor calado pedagógico. Nuestro propósito es doble. Por un lado, se trata de elaborar un breve trazado conceptual sobre lo que, en general, se quiere expresar hoy, desde la filosofía, cuando se dice que el sujeto está en crisis. Por otro, se pretende reconocer en el pensamiento y la acción educativa las diversas manifestaciones, incidencias, tendencias o tensiones, si las hubiese, desde el modo en que se ha sometido a crítica la idea de sujeto, que alertan al sistema educativo o, por lo menos, a quienes nos dedicamos profesionalmente a este campo.

Si siempre hemos mantenido, con mayor o menor énfasis, que lo que empieza por vociferarse en las ciudades académicas termina, en muchas ocasiones, por invadir los canales de comunicación de las plazas pedagógicas, nos ha llegado ya la hora de confirmar o desmentir esta tesis. Aunque, como señalaba hace unos años Ruth Jonathan, «llegar a saber qué vinculación media entre los valores y las propuestas (y, por tanto, en los programas educativos implicados) que pudiese ser aprobado por la sociedad, no es un asunto para la lógica, el cálculo o los expertos, sino de promoción de un debate en el foro público donde compiten valores e intereses", también interesa señalar, no obstante, y esta autora lo hace en el mismo

1. Algunas de las ideas de este artículo fueron redactadas inicialmente como mi contribución para la elaboración colectiva de la ponencia "La crisis de la sociedad actual" presentada en el XX Seminario Interuniversitario de Teoría de la Educación, Conflicto, Violencia y Educación, celebrado en Murcia del 19 al 21 de noviembre de 2001 (Jover, Casares, Gil y Payá, 2001, 23-75). 
texto, que una de las funciones de la reflexión pedagógica estriba en "delimitar los costes conceptuales (y nosotros añadiríamos prácticos) que han de pagarse por las modificaciones en nuestros valores y propuestas" (Jonathan, 1992, 298 y 299; cursiva añadida). Éste es el propósito del presente artículo frente a la crisis del sujeto ${ }^{2}$.

Para empezar adoptaremos una recomendable precaución pedagógica ante la investigación filosófica. Cuando los filósofos hablan de crisis del sujeto no están, por lo general, pensando en ti, lector, sino en una idea trascendental de sujeto. Por eso, lo que se trata de precisar en este caso no es la crisis del sujeto, a secas, sino en rigor la crisis-de-la-idea-de-sujeto. Pues bien, los filósofos han puesto en solfa las ideas en torno al sujeto enviando tres venerables perspectivas filosóficas a cuestionar lo que el hombre piensa (filosofía de la razón), lo que el hombre dice (filosofía del lenguaje) y lo que el hombre hace (filosofía de la moral) ${ }^{3}$.

\subsection{La crisis de la idea del sujeto-razón}

La crisis del sujeto, en tanto que ser-pensante, se centra ${ }^{4}$ en desacreditar las casi ilimitadas posibilidades que la Ilustración inicial y, especialmente, la modernidad de finales del XIX y principios del XX otorgaban a la razón. Es una puesta en crisis del logos universal y del logos individual. El principio de poder hallar claves interpretativas con validez espacial y temporal es cuestionado radicalmente ${ }^{5}$. La

2. Diferentes versiones de este debate pueden rastrearse, entre otras referencias, en: Agamben (1998); Arendt (1993); Bárcena y Mèlich (1999); Crespi (1996); Cruz (1996); Delacampagne (1999); Derrida (1994); Duch (1998); Finkielkraut (1998); Gergen (1996); Jiménez (1989); Larrosa (1996); Levi (1998); Levinas (1977); Magris (2001); MacIntyre (1987); Muguerza y Cerezo (2000); Pinillos (1997); Ricoeur (1996a, 1996b, 1997); Taylor (1994, 1996); Terrén (1999); Zambrano (1989)...

3. Esta distinción metodológica tiene una utilidad pedagógica que no vamos a desarrollar pero que interesaría tener en cuenta en otras investigaciones. La razón, el lenguaje y la acción constituyen, como es sabido, los pilares antropológicos básicos del currículo y ulteriormente de nuestros programas de intervención educativa, lo que implica que se podrían analizar las incidencias de la crisis de la idea del sujeto a través de cada una de las áreas curriculares, su contenido, objetivos, la presencia o ausencia de ciertas materias transversales, el predominio de ciertos recursos didácticos, etc.

4. Utilizamos la forma verbal del presente para facilitar la lectura, asumiendo, como es evidente, que habrá factores que ya pueden ser remitidos al pasado, mientras que otros deberían ser expresados, tal vez, en un presente continuo.

5. Como es sabido, Nietzche es, históricamente, el autor que aglutina casi todos los discursos críticos y hasta negadores de la razón, aunque para comprender el alcance de sus ideas hay que situarlas en Hegel y la filosofía romántica con su pensamiento sin referente o certezas. Pero el hilo conductor de este artículo trata de reflejar, desde una perspectiva pedagógica, precisamente, el tema central de la crítica a la modernidad, que no se queda en la razón, el lenguaje y la moral, sino que se concreta sobre todo en el supuesto agotamiento de la filosofía del sujeto y, en concreto, aunque tendrá una versión pedagógica diferente, como veremos, en el resurgir de las filosofías de la diferencia que, con Heidegger a la 
causa principal, desde un punto de vista filosófico-epistemológico, se sitúa en el avance gnoseológico de la ciencia que se apropia de la demostración de verdad empírica echando sobre lo filosófico una debilidad profunda de prueba. Ahora bien, la crisis de la filosofía de la razón no surge sólo de su incapacidad para situarse a la par del progreso del conocimiento científico sino por la vía misma de indagación que adopta ante su permanente minoría de edad frente a lo empírico. En efecto, la filosofía de la razón pasa de una posición de resignación teórica - la filosofía ha llegado a su fin- a una posición de autoafirmación engrandecida de sus propias limitaciones: la filosofía del pensamiento débil, de lo cotidiano, de lo frágil, de las experiencias $^{6}$. La modernidad ha arrasado científicamente y los filósofos han sido desterrados otra vez. Surge así el hueco para escaparse de la losa cientificista: cuestionar las bases universales, epistemológicas, de la modernidad y sustituirlas por otras más localistas, más fragmentadas, más relativistas.

La crisis de la razón es una crisis de la razón total, universalista y uniformadora. Es una crisis del pensamiento tecnológico posibilista, de la verdad con mayúsculas. Es un ataque a un logos engreído, objetivizador e ilimitado. Lo que se trata de recuperar o, si se quiere descubrir, es el otro lado de la razón, la sinrazón del disenso, de la subjetividad, de la ocurrencia, de la apariencia, de la imagen, de la metáfora, de lo indeterminado, etc. Con la razón moderna el sujeto se atiene y reconoce el orden establecido, las secuencias, las consecuencias, los premios y los castigos, las leyes, las normas; es un ser autónomo vinculado a un Todo. Con la razón posmoderna, el sujeto construye, establece sentidos, quita y pone fines a lo que ve, hace y lee, elabora interpretaciones; es un ser casi sin vinculación a nada ni a nadie, como mucho, a sí mismo y a los "suyos".

No es necesario insistir; dice Duch, en el hecho de que, a pesar de los numerosos intentos fundamentalizadores que se perciben en nuestra sociedad, es decir, a pesar de la "no imposible restauración", vivimos en un mundo cuyas fundamentaciones tienden a dejar de ser los puntos de referencia obligados de la vida de los individuos y de los grupos sociales, para convertirse en meras "opciones" que, a menudo, poseen una pequeñisima influencia en los asuntos sociales y culturales de nuestros días. Aquí se concreta, en realidad, el "paso a lo relativo" (Duch, 1998, 14-15).

Hemos señalado que la crisis del sujeto pensante fue universal e individual. La crisis en el sujeto concreto considera la razón como incompleta porque, entre otras cuestiones, le falta la consideración particular del mundo emocional, de las

cabeza, llegará a la filosofía de la deconstrucción de Derrida con la imposibilidad de un sujeto unificador. Éste es el planteamiento de fondo hoy más reconocido y aceptado, sin embargo, hay otros enfoques diferentes sobre la crisis del sujeto, que retoman una literatura generalmente ausente en este debate: Bürger y Bürger, 2001.

6. De hecho, los filósofos que no han aceptado esta vía se han dedicado a seguir la estela de la hermana mayor del conocimiento y se han convertido así en filósofos de la ciencia y de la tecnología. 
pasiones, de los sentimientos. La modernidad habría dado la imagen de que el hombre es un ser ulteriormente razonable que puede abrazar el horizonte argumental de una opción frente a otra. La posmodernidad pretende centrar más globalmente esta posición: el hombre lo que hace sobre todo es sentir su vida y sus experiencias, no es un ser que anteponga su juicio incontaminado de pasiones sino al revés, es un ser que se mueve siempre estimativamente, por valores o preferencias emocionalmente deseadas o, en su caso, rechazadas y, aquí está el meollo de la posmodernidad: no se le exige ya al sujeto que razone mediante claves intersubjetivas de análisis sus simpatías y sus odios, más bien se le anima a que viva su vida, a que adopte sus vicios particulares y module, eso sí, sus comportamientos con los demás cuando la situación lo requiere. "Mi familia", "mis amigos", "mi pareja", "mis hijos", "mi ocio y tiempo libre", "mi trabajo".., son los pilares posmodernistas de la razón humana.

El pensamiento débil en su forma explicativa universal o individual es la exaltación democrática de la mediocridad de la inteligencia. Como señala Magris, "(t)ambién parece estar en peligro, a pesar de la creciente racionalización técnica, la racionalidad, hostigada por un cada vez más difuso irracionalismo, por un amasijo de ocultismo y superstición" (Magris, 2001, 287). Muchos filósofos no se han dado cuenta porque siguen mirando poco a la realidad pero, posiblemente, estemos ante uno de los casos en que la filosofia ha generado una reflexión que está en la calle, que es generalmente aceptada y, sobre todo, cuya práctica sirve de laboratorio de ideas para el pensamiento filosófico.

Cuando la Filosofía pone en crisis a la razón provoca un repliegue individual de la misma por lo que los sujetos tienden a sobrevalorar las opiniones personales como dignas de respeto en sí mismas. Las ideas se constituyen así no en aproximaciones a una verdad, no son expresiones de búsqueda de un logos universal sino un mundo en sí mismo, una especie de posesión y construcción de la persona. Parece como si el sujeto fuese, metafísicamente, la opinión que sustenta, de tal modo que se hace difícil cuestionar y, más aún, desacreditar esa opinión sin que se tache de intolerante a quien contrargumenta y descalifica las opiniones de que se trate. Llama la atención que esto ocurra, precisamente, en el contexto de un pensamiento débil donde cabría suponer que el pensamiento es intercambiable, perecedero, sujeto a mutación constante y hasta relativista. Y, sin embargo, ocurre... por esa misma razón. En efecto, allí donde no hay la vivencia de la posibilidad de una certeza, donde no se vislumbra una jerarquía de valoración de opiniones y argumentos, las ideas u opiniones, cuando se tienen, quedan encapsuladas, idolatradas como bienes escasos y de término, cuyo cuestionamiento provoca una inseguridad existencial insoportable, un hueco, un vacío, un no ser. No importa carecer de opinión sobre ciertos temas, pero si se tiene, el sujeto-es-lo-que-piensa. El relativismo, tan denunciado, no parece, por tanto, que tenga su origen en una posición filosófica sólida. Más bien, es el resultado de una posición existencial. Todas las opiniones son respetables porque están personalizadas, hay siempre alguien detrás de las mismas, pero carecen de validez universal. 
La "autonomización" de la razón implica que en las situaciones educativas, como desarrollaremos más adelante, nos estemos encontrando con una cierta autocomplacencia intelectual en la que "el problema, después de todo, no son las voces que hablan sino los oídos que no escuchan" (Cassey, 1995-1996, 223). "No se trata sólo -dice Altarejos- de incapacidad psíquica de escuchar, de oír, aunque ésta sin duda es un efecto: es falta de atención en el sentido fuerte de la frase española "no atender a razones". Se escucha, se oye, e incluso se entiende de oído; pero no se atiende a ello" (Altarejos, 1999, 75). El criterio de autoritas está desapareciendo, todas las opiniones son respetables. Lo que supone que la condición de agente intelectual en el alumno se elabora mediante amplios criterios de construcción y pocos criterios de escuchar y asumir otros discursos y otras opiniones. "La época de los conocimientos rotundos - dice Pinillos- se ha terminado: nadie tiene autoridad para hablar en nombre de todos. Urge impedir que un discurso pueda imponerse a otro" (Pinillos, 1997, 244). Las "tradicionales pautas de transmisión" (Duch, 1998, 68) entran en crisis porque, entre otras razones, se ha sustituido la escucha atenta y deliberativa por el debate en el que todos tienen la misma condición de generadores de opinión. Discutir una posición ya no es criticar el punto o la dirección de una argumentación sino cuestionar al propio ser del sujeto porque éste ha dado por cerrada su relación con la realidad en el mismo momento que opina. La autocomplacencia intelectual es el aislamiento engrandecido y orgulloso de un estilo de vida que abarca un círculo existencial y cognitivo muy estrecho. «El mundo, el todo soy yo y los míos, y mi papel de sujeto-razón es pensar en mí y en los míos". ¿Quién no ha experimentado en las aulas universitarias la preeminencia total de la razón privada frente a la pública, frente al logro de unas claves intersubjetivas de análisis? ¿Quién no ha observado el desequilibrio existente en las demandas escolares entre una educación intelectual rigurosa y, pongamos por caso, una educación para debatir?

\subsection{La crisis de la idea del sujeto-lenguaje}

La Filosofía también ha sometido a crítica al sujeto en su dimensión de ser hablante. Para algunos autores, como Duch, «(q)ue la crisis global del momento presente pueda ser calificada de crisis gramatical es algo que nos parece fuera de cualquier duda" (Duch, 1998, 460, cursiva del original). La exaltación posmoderna de la diferencia, entre otras razones, ha llevado al pensamiento filosófico a girar la mirada de admiración hacia lo más diferente y permanentemente innovador de la expresión lingüística: la literatura y dentro de ella la profusión imparable de metáforas, juegos lingüísticos, imágenes literarias, etc. ${ }^{7}$. El conocimiento se obtiene también

7. Ésta es, probablemente, la expresión última de la trayectoria idealista —contraria a la realista de Peirce - iniciada por Ferdinard de Saussure para quien los signos lingüísticos sostenían cierta relación con la realidad a la que nombraban. Luego el posestructuralismo al 
de sumergirse en la imaginación de los novelistas. Cada texto es una realidad en sí misma, diferente de las demás, un mundo de evocaciones, de múltiples lecturas e interpretaciones; cada nuevo lector es el desencadenante de un nuevo texto sobre el texto original, una nueva interpretación y visión. El texto no se refiere a la realidad, la configura. Poner al sujeto en crisis como ser hablante significa, desde las tesis de la posmodernidad, acentuar su individualidad presente hasta la posición de reconocerle autor, poeta de su vida. Gran parte de la filosofía actual desconfía de las interpretaciones universales, de los grandes relatos, de las narraciones ejemplares y maestras de la vida, "el lenguaje ya no parece como un camino hacia la verdad demostrable, sino como una espiral o una galeria de espejos que hace volver al intelecto a su punto de partida" (Steiner, 1990, 44). Se queda con los relatos menores, más aún, con la visión de que cada sujeto es autor de su texto y como lector es un reconfigurador permanente de las imágenes literarias y, por tanto, desde esta perspectiva, de la realidad. Pero todavía hay más: es un lector-creador de la realidad, uno más, un permanente intérprete de las sucesivas relecturas que haga de los textos y ulteriormente un permanente creador del mundo, de su mundo ${ }^{8}$.

mantener la ausencia total de relación entre el lenguaje y su significado, abrirá el camino del deconstruccionismo de Derrida. El lenguaje no tiene esencia, él es su propia esencia. El texto es un mundo en sí mismo y su significado una arbitrariedad cultural, contingente, no hay ya grandes relatos. Para Derrida la importancia de los textos está en los mismos signos y no en que éstos remitan a un sentido, una verdad o una razón. Según este autor, la cultura occidental, se encuentra encerrada en la perspectiva hermenéutica, según la cual, tendemos a pensar que detrás de cada texto hay un sentido último, una verdad o una falsedad que tenemos que descubrir, una "metafísica de la presencia". Para Derrida hay que oponerse a esta tendencia, pues nada hay fuera de los textos, e iniciar el proceso de la deconstrucción o desargumentación de los sentidos vistos con anterioridad al texto, para lograr quedarnos, dirá, con el sentido inmanente al propio signo (Derrida, 1994, 371).

8. La demanda actual tan vigorosa de adquirir el hábito de la lectura es, no cabe duda, un acierto a mantener y extender. Pocos mensajes pedagógicos son más necesarios hoy que despertar en las nuevas generaciones la pasión por leer. Sin embargo, permítasenos la sospecha de que en no pocos casos, la lectura es, en clave posmoderna, la actividad deconstruccionista de oponerse a la tiranía de la razón y, ulteriormente, de alejarse del valor educativo de las acciones reales, no imaginadas. Como dice Pinillos, siguiendo las tesis de Hassan, la lectura se defiende hoy desde la perspectiva de la ironía radical, el rechazo total de la representación, la repulsa del orden y la finalidad, es la aceptación del azar, la improvisación y la indeterminación de lo real; “leer bien consistirá en oponerse a la tiranía de las totalidades, dado que toda totalización es totalitaria en potencia" (Pinillos, 1997, 201). Los tiempos actuales muestran a la literatura no sólo como una forma de entretenimiento ni de conocimiento sino como fuente de un tipo de razón peculiar, acorde con la crisis apuntada. Desde esta perspectiva, leer o escribir no supone tener que alcanzar algún último sentido verdadero sobre sí mismo o la realidad. Para Derrida, el buen lector o escritor es el que huye de la captación de sentidos porque todos los sentidos que puedan hallarse son igualmente legítimos. Cuando el lector o escritor realiza el proceso de deconstrucción correctamente lo que consigue es encontrarse y quedarse con la referencia estética de los signos. La referencia del texto será así un gesto sentimental y emotivista en la recepción de la lectura o escritura que "ofrecerá" sentidos e interpretaciones en función de los estados subjetivos del 
La Filosofía como texto, el sujeto como lector y autor e incluso, es menos metáfora de lo que pueda parecer, el sujeto como texto, supone también asumir y asegurar de algún modo su metamorfosis permanente. De la relativa estabilidad ontológica de la modernidad hemos pasado al paroxismo del cambio y la mudanza. De la voz racionalista hemos pasado a asumir las voces que nos pueblan, tantas como papeles queramos mantener. Entre tanta voz no cabe buscar la del máximo sentido y mucho menos reconocer en otras una argumentación más acertada, pues supondría en ambos casos invalidar el resto, lo que carece de lógica en el horizonte posmoderno. La crisis del sujeto vuelve aquí a manifestarse de un modo muy peculiar: entre tanta voz lo que hay que tratar, en clave literaria y narratológica, es elaborar el personaje.

El uso generalizado del término personaje en los textos filosóficos posmodernos es desconcertante. El personaje carece de suyo de cualquier fijeza ontológica, es un sí mismo referencial al contexto, a la tradición, a la comunidad de origen o a la narración particular, es un "devenir-ausente" (Derrida), una "ausencia real" ". Las figuras literarias radicales del personaje son la memoria y la imaginación. El personaje es un debutante permanente de la acción porque aparece y desaparece y cuando se hace presente ya no tiene que ser o parecer el que era, puede ser otro, otra, con unos rasgos o con otros. El personaje desontologizado, desarraigado del Todo de la modernidad, lleva a la figura hablante del vagabundo ( somos básicamente vagabundos Pereda, 1998, 185; cursiva del original), al ser errante, permanentemente en camino, a un proceso de ser sin referencia estable, a una dispersión de la subjetividad, que trasmite un sentido huidizo e inaprensible de la existencia. La crisis de la idea de sujeto-lenguaje encuentra su última expresión en la filosofía analítica sobre los marcos de referencia lingüística, en el que el hablante no se encuentra ya, su discurso, en las condiciones de verdad sino en las condiciones de

lector o escritor. Como afirma Derrida en su libro Márgenes de la Filosofía, "(1)a escritura se lee, no da lugar, "en última instancia", a un desciframiento hermenéutico, a la clarificación de un sentido o una verdad" (Derrida, 1994, 371). Lo mismo cabría decir de la tendencia en la sociedad actual a que cada ciudadano sea un escritor en potencia, o a que las ventas más millonarias de las editoriales sean los textos biográficos en sus diferentes formas. Aquí se oculta la tendencia denunciada ya en la filosofía pero presente también, como veremos, en nuestro ámbito pedagógico, de que "la relación de la tradición con un nuevo texto filosófico es la misma que la relación de la tradición literaria con un nuevo texto de literatura: no hay paso normativo entre uno y otro" (Villacañas, 2000, 369). Algunas propuestas posmodernas son muy acertadas para señalar el núcleo adulto" de la experiencia de la lectura, pero, desde una perspectiva pedagógica, a veces olvidan el pequeño detalle de diferenciar los juegos de las identidades, del difícil y largo proceso de lograr una primera identidad, fuerte y estable.

9. La separación y hasta la ruptura entre el lenguaje y el mundo, «la crisis del significado del significado" (Steiner, 1989, 122) ha originado "el peligro que ahora mismo asedia al lenguaje humano (que) se puede resumir en una expresión: ausencia real. En lugar de ser el vehículo de la presencia, las expresividades humanas, con frecuencia, se han transformado en señales de vacio; el vacío en forma de opresión, de vulgaridad, de desmantelamiento de las creencias, de perversión de las palabras más sublimes" (Duch, 1998, 461; cursiva del original). 
afirmación. El vagabundo está instalado en la pura autoafirmación del presente como experiencia de vida, desarrollando la afirmación de sus vivencias.

Como ha tratado Taylor, cuando al yo presente se le ha arrancado su identidad constitutiva, tenemos un yo puntual, desvinculado, desarraigado, neutro y, por tanto, "Cómo nos consideramos a nosotros mismos en última instancia es una cuestión arbitraria" (Taylor, 1996, 66). Una de la influencias básicas del estructuralismo en el pensamiento filosófico es el reconocimiento de que el hombre no puede seguir concibiéndose a sí mismo como sujeto, dueño de sí mismo y de su mundo. Influencia que en clave posmoderna se extiende a una clara disolución de la subjetividad, identidad y razón humana. En efecto, si alguna ventaja está teniendo la imparable producción bibliográfica sobre posmodernidad estriba en que se está llegando a un gran acuerdo acerca de algunos síntomas peculiares de nuestra época. Muchos autores coinciden en destacar que nos encontramos inmersos en concepciones de valores individualistas que tienden a concebir al hombre como un "microcosmos" autosuficiente. Estas actitudes serían para algunos una consecuencia inevitable, por un lado, del carácter esencialmente fragmentado, huidizo y cambiante de la vida y, por otro, del derrumbe de las ideologías, de las comprensiones globales de la realidad y, ulteriormente, de la pérdida de la esperanza de encontrar alguna verdad estable.

Ante un futuro incierto, se dirá, sólo cabe el asidero del relato de la propia vida como medida de certidumbre.

Hemos aprendido — dice Jiménez- que el hombre no es, deviene: somos ante todo, transformación, metamorfosis [... Reivindicar hoy la memoria no significa pretender, ingenuamente, volver a la ilusión de un "gran relato". Pero sí tomar consciencia de los "los relatos" operativos [...] Naturalmente, no en términos de sustantividad y homogeneidad, sino de formatividad y pluralidad. Somos "prosa" al tiempo que "poesía": relato y metáfora, memoria y exploración (Jiménez, 1989, 24-25).

Desde estas ideas cualquier debate acerca del papel del hombre como actor o autor es algo más sustantivo y determinante que una mera metáfora literaria. Nos encontramos ante toda una concepción de la condición humana y ante una imagen de futuro de lo que el hombre es y debería llegar a ser. Vivir, se dirá, no es lograr una identidad sino en la línea de los llamados deconstruccionistas asumir la esencial desidentificación del hombre. Somos pura transformación, una metamorfosis permanente por lo que vivir y vivir con sentido es el relato ulterior de una elección. "Crecientemente - afirma Jiménez- nos vemos a nosotros mismos como actores que, en el escenario del mundo, no interpretamos un papel único. Podemos ser compasivos o crueles, tiernos o duros, formales e informales y, en fin, femeninos o masculinos, según la situación y los demás participantes de la escena que vivimos. Somos una metamorfosis continua, y cada vez nos hacemos más conscientes de ello" (Jiménez, 1989, 192). Gergen se pregunta y se contesta de igual modo: 


\begin{abstract}
¿Se reduce el individuo a ser un estafador social, adoptando cualquier postura de identidad que recoja la mayor recompensa? [... .] Desde el punto de vista construccionista, la relación adquiere prioridad sobre el yo individual: los yoes sólo se realizan como subproductos de la relación. Por consiguiente, cambiar la forma y el contenido de la autonarración de una relación a otra, no es ni fraudulento ni egoísta en el sentido tradicional. Más bien es honrar los diversos modos de relación en los que uno está cogido (Gergen, 1996, 303).
\end{abstract}

Como dice Rorty, si bien creo que una correcta interpretación historicista lo negaría, "(p)ara los antiesencialistas, todos los fines posibles compiten entre sí en pie de igualdad, pues ninguno es más "esencialmente humano" que los demás" (Rorty, 1996, 152).

Somos, se ha dicho, una metamorfosis, por lo que podemos ser cualquiera de los autores y actores que nos pueblan, y ese poder-ser será el relato de una elección. Dicho en pocas palabras: todo vale, toda elección es valiosa porque todo es ulteriormente narrable como una historia de vida particular. Una de las causas de este error, que tiene, como veremos, implicaciones críticas para la educación, estriba en no advertir que «la problemática en torno a la palabra no queda restringida al campo de las expresiones [...] como frecuentemente se ha dicho, sino que alcanza la totalidad del ámbito de la responsabilidad bumana, es decir, toda la existencia bumana (Duch, 1998, 479; cursiva del original) ${ }^{10}$.

Probablemente una de las incidencias conceptuales y prácticas más llamativas de la crisis de la idea de sujeto-hablante en la educación consiste, como veremos más ampliamente, en que hemos perdido nuestro objeto de estudio. La pérdida de los contornos de significado de muchos aspectos de la realidad, está incidiendo en la educación en el sentido de que, sin alarmismo alguno, nos hemos alejado de la indagación acerca del significado preciso de la educación y más aún de lo que significa que una persona esté educada. La Pedagogía, como todos los saberes contingentes, ha desdibujado la firmeza de su objeto de estudio al tratar de conseguir que respondiese a todo tipo de expectativas sociales. La comunidad educativa sigue siendo un recipiente de propuestas o fines sin que, de suyo, podamos mantener, todo lo contrario, que se confía más en la labor de los educadores y de la escuela. El campo conceptual y práctico de la educación ha perdido sus contornos precisos, su delimitación clara de qué actividades educan y cuáles no, y esta deriva sin anclaje favorece que se vuelque en nosotros, los educadores, todo tipo de expectativas.

10. Sábada ya lo vio con claridad y acierto hace unos años cuando nos advertía de la necesidad de "deshacer una posible mala interpretación respecto a la moral como un juego de lenguaje más. Posible mala interpretación que se apoyaría en una real mala interpretación bastante frecuente y que consiste en insistir tanto en las diferencias, en los espacios cerrados de los juegos de lenguaje, que se pasa por alto la universalidad que les atraviesa no en cuanto juegos de lenguaje diversos sino en cuanto bumanos (Sábada, 1989, 171; cursiva del original). 


\subsection{La idea de la crisis en el sujeto-moral}

Finalmente, los filósofos han puesto también en crisis al sujeto en su dimensión moral. Tal vez sea aquí donde más se manifiestan y, en ciertos casos originan, algunos de los factores señalados previamente.

La línea base de esa crisis estriba en acentuar la moral privada. La autonomía moral kantiana de la modernidad alcanża ahora su máxima expresión individual al renunciar a la propuesta universalizadora del imperativo categórico. Al sujeto se le pone en crisis en su dimensión moral al dejarlo solo, sin referencias categoriales estimativas, al suprimir las consecuencias morales de sus actos. Cada sujeto es autor de su vida y el valor de la misma radica en su atrevimiento moral, en hacer lo que quiera sin el horizonte teológico asfixiante del pecado. El sujeto se redime a sí mismo, es juez y parte, todo queda en casa... y no pasa nada, o en cualquier caso, no es grave, no tiene importancia.

La responsabilidad carece de peso existencial porque ya no se trata de rendir cuentas. La autoría de la acción de un sujeto que es personaje es una autoría interesadamente anónima y fantasmagórica y, como tal, cambiante, modulable, puede aparecer o desaparecer, hacerse afirmativamente presente o ocultarse. La afirmación del yo es una cuestión lingüística, como mucho alcanza las posibilidades de acción pero no las consecuencias morales de la misma. El eslogan antropológico ya no es "nos vamos haciendo según actuamos" sino "soy lo que pienso de mí mismo" y mejor aún en presente continuo "soy lo que voy pensando de mí mismo".

El ser es ya una categoría cognitiva: pienso que soy lo que recuerdo, pienso que soy lo que imagino, pienso que soy lo que... pienso. Recordar, imaginar, pensar, soñar, se hacen claves introspectivas del personaje perseguido con lo que el refugio moral de los intelectuales, su fuente de conocimiento ya no es la ciencia, la naturaleza o la cultura, sino, como señalamos, la literatura, la novela y, en especial, las memorias, las autobiografías. El mundo ya no se explica desde la filosofía sino que se cuenta desde la literatura, la memoria y la imaginación.

Poner al sujeto en crisis en su dimensión moral estriba, precisamente, en poner en paréntesis el logos moral, la razón explicativa de lo bueno y poner en cambio en mayúsculas el relato moral, la novela ejemplar, en fin, el contar las experiencias, en relatarlas. "[...] Resulta -dice Pinillos- que son el posmodernismo y el mundo actual los que precisamente rechazan la idea de totalidad, cuando es claro que sin algún tipo de totalización la acción moral es imposible, y la responsabilidad colectiva no encuentra el vigor necesario para su actuación" (Pinillos, 1997, 319). La ejemplaridad, el modelo egregio, la élite moral se democratiza: cada vida contada es una vida moralizada, experimentada, es un relato en sí mismo valioso, valorable en su contorno vital. La moral como contenido no son criterios a los que el sujeto se acerca o se aleja: la moral como contenido es el relato de la intimidad del sujeto. El sujeto moral vuelve a ser, como veíamos antes, su palabra, su historia, su voz. El mercado ha captado perfectamente esta tendencia: el dinero se sitúa hoy en quien, como famoso, se hace memorialista de su vida y 
se descubre ante los demás. Lo que oye con atención el sujeto son las historias de otros, lo que se compara no es la bondad moral del acto, sino las experiencias vitales. Desde la filosofía, el logos siempre se ha hecho palabra pero ésta no era el criterio último de la razón. Ahora sí: la palabra es el logos cuando es la voz de una vida, para llegar a elaborar un personaje.

Los que silencian sus vidas ante los demás, los que no relatan experiencias vitales rompen el impulso nivelador de las relaciones entre sujetos, son unos extraños, los extranjeros del grupo. Quien no supera los residuos modernistas del pudor existencial, quien cultiva una intimidad no pública está creando espacios de sospecha, de desconfianza y, sobre todo, si se analiza desde la perspectiva moral de la crisis del sujeto, se está deshumanizando, no es tan humano. Quien no se cuenta no cuenta. La modernidad tardía en clave habermasiana nos legó la imaginación del interlocutor invisible pero existente, la voz de sus intereses reales, la posmodernidad tardía nos está legando que el sujeto fantasma, el personaje, el que no está pero podría estar, es la memoria de vida, de su vida, lo que requiere una voz que recuerde una trayectoria existencial.

Si el sujeto se hace al contarse, la comunicación crece vertiginosamente en todas las direcciones. La sociedad es así la de la información, la del chisme, la del bla, bla, bla. Más libros, más revistas, más canales de televisión, más teléfonos, más páginas web, más debates, más periódicos, más propaganda-anuncios, más canales de radio, más cafeterías, etc. El ruido es ya tan alarmante y asfixiante que han surgido los filósofos del silencio, los creadores de espacios literarios en blanco, los cultivadores de la mirada callada y atenta, los fugitivos de la barbarie sonora. "En la era de la comunicación, el silencio es el paréntesis del ruido, aunque no el pliegue por el que se cuela la melodía de un encuentro cara a cara [...]. Este silencio incómodo para una modernidad emborrachada de ruidos y de palabras-fórmula que declinan el "decir" ocultándose en lo "dicho" [...]" (Bárcena, 2001, 191).

Al descentrarse ("significados flotantes") los términos morales tradicionales, la moral como estructura - el hombre es un vagabundo- y la moral como contenido - todo vale si tú lo quieres-, la consecuencia inmediata es el relativismo. Pero un relativismo vital y existencial: no se trata de que no podamos fundamentar lo bueno en sí mismo y, por tanto, que toda opción esté desarraigada de un factum moral, sino al revés, el fundamento de lo bueno lo determina el mismo sujeto en la medida en que su opción le valga para vivir. La autoría de la acción que veíamos antes, la construcción de sentidos y el pluralismo social inducen a traspasar el protagonismo moral último al sujeto, quien se sitúa así en la búsqueda de umbrales de autosatisfacción. La regla moral definitiva hoy es el propio bienestar, la autocomplacencia, porque "(v)ivimos en un mundo de aislamiento del individuo en su yo y de pérdida del interés por los demás o por la sociedad [...]" (Ortega y Mínguez, 2001, 15). No cabe duda que "(1)a cultura de la obligación ha dado paso a la ocupación en la "gestión integral" de los propios intereses" (Escámez y Gil, 2001, 21) porque, como señala Ibáñez-Martín, "(p)rimero se desprestigió intelectualmente la idea de la responsabilidad personal [...]. A la crisis de la 
responsabilidad, se ha sumado la crisis del sentido de la libertad, de la necesidad de identificar aquellos bienes - no siempre gustosos- que nos llevan a una vida verdaderamente buena, a una vida examinada, como decían los clásicos" (IbáñezMartín, 2001, 445).

En realidad, la tan debatida crisis moral del sujeto alcanza su expresión más sintética en un planteamiento estrictamente pedagógico y, por cierto, con mucha solera como saben todos los educadores: "La paradoja de la autodeterminación de este yo moderno reside en que se sabe, por una parte, como ser individual que es absolutamente diferente de los demás hombres, que se esfuerza, por otra, en vano, sin embargo, por darle a este saber una forma concreta. Pues no es capaz de decir lo que es" (Bürger y Bürger, 2001, 152; cursiva del original). Y es que "no podemos ejercer nuestra subjetividad y ser conscientes de un mundo sin una idea de nosotros mismo como sujetos encarnados" (Taylor, 1997, 50).

Se suele decir que uno hace con su vida lo que quiere, y así es. También que uno hace con su vida lo que quiere mientras no haga daño a nadie, y así es. Pero este principio olvida que si bien permite elaborar una identidad, paradójicamente, impide tener-claro esa identidad. Yo soy quien soy, e incluso soy quien quiero ser. Pero ocurre, sin embargo, que la identidad es una labor de referencia externa reconocida y reconstruida, esto es, mi identidad apunta a mi subjetividad pero desde fuera de ella misma, es la fusión de una representación mimética y de una interpretación valorativa de otras posibilidades (identidades, narraciones, voces, memorias, valores, tradiciones, etc.). De este modo, mi identidad, mi yo, mi estilo de ser, mi subjetividad, se oculta y pierde claridad de fines en la medida que me empeño en silenciar y apartar toda referencia externa valorativa. Odo Marquard lo señala indicando que

(1)o mismo le sucede a quien busca directamente la felicidad (bajo el seudónimo de sentido): pues una persona así no quiere leer, sino que quiere sentido, no quiere escribir, sino que quiere sentido, tampoco quiere trabajar, sino que quiere sentido, ni quiere holgazanear, sino que quiere sentido, ni quiere amar, sino que quiere sentido, no quiere ayudar, sino que quiere sentido [... . Ningún ser humano accede inmediatamente al sentido; los seres humanos siempre acceden al sentido a través de mediaciones (Marquard, 2000, 59-60; cursiva del original).

Por su parte, Ricoeur, nos sugiere también que "(e)n nuestros días, vemos que la idea misma de una mediación institucional de la libertad retrocede en los pensamientos y deseos. Nuestros contemporáneos están cada vez más tentados por la idea de una libertad salvaje, fuera de las instituciones, mientras que toda institución les parece de naturaleza esencialmente coercitiva y represiva" (Ricoeur, 2001, 235).

La idea de la crisis en el sujeto-moral es, como veíamos, una crisis de mediaciones, en este caso, de mediaciones valorativas sobre lo bueno para el hombre en tanto que hombre. No me gustan los sustancialismos antropológicos desencarnados, pero creo que descentrar al hombre, como hace la posmodernidad, es más de lo mismo pero en otra dirección. También nos equivocamos cuando, como suele 
ser habitual en los discursos pedagógicos en los que por mucho que les pese a algunos tenemos que pensar en la formación humana en términos éticos y de proceso, nos limitamos a configurar encarnaciones vacías, apoyadas en buenas palabras y voluntades, sin argumentos que prueben racional e históricamente que, en general, el hombre prefiere vivir bajo determinados valores que empujan y elevan su desarrollo humanizador.

La crisis de la idea del sujeto-moral se muestra desde una perspectiva pedagógica, como veremos, precisamente al reconocer que no nos estamos tomando suficientemente en serio la profunda mediación valorativa de la educación, con lo que, en ocasiones, nos vemos empujados a apropiarnos acríticamente de discursos muy llamativos (como el de la crisis del sujeto) y hasta aplaudidos por el entorno intelectual y el mundo de los adultos, pero de escaso valor pedagógico para los educadores y la infancia.

Lo que me interesa señalar y ampliaremos en el apartado siguiente es que mientras nos regodeamos intelectualmente con vaciar al hombre y jugar al yo-yo, otras instancias con menos remilgos filosóficos están ofreciendo gangas para llenar esos vacíos. Nos hace falta una pedagogía de la resistencia creativa, que nos recuerde las dificultades intelectuales para fundamentar los discursos éticos, pero sobre todo que nos recuerde también las irrenunciables responsabilidades pedagógicas actuales que tenemos con las nuevas generaciones. No nos podemos quedar sólo en una parte del debate ("somos básicamente vagabundos"), hay que llegar sobre todo a la otra: "Pero soñamos con no servagabundos" (Pereda, 1998, 185; cursiva del original). La pedagogía tiene que saber atender con sentido de acogida los plurales deseos de los sujetos por llegar a ser, pero también hace falta ya que con cierta determinación no arrogante, muestre, sin claudicar, la difícil pero imprescindible relación entre lo que queremos ser y lo que somos. Como señala Magris, es "necesario un pensamiento anti-idólatra, un pensamiento fuerte capaz de establecer jerarquías de valores, de elegir y por consiguiente dar libertad, de proporcionar al individuo la fuerza de resistir a las presiones que le amenazan y a la fábrica de opiniones y eslóganes [...] sólo una jerarquía de valores puede impedir que el Yo individual pierda su unidad y solidez y se diluya [...]. (Magris, 2001, 287).

\section{LA EDUCACIÓN DESDE LA IDEA DE LA CRISIS DEL SUJETO}

Lo que tenemos que preguntarnos ahora, a la vista de los análisis previos, es cuáles pueden considerarse hoy esas tendencias o tensiones — desde el modo en que se ha sometido a crítica la idea de sujeto- que alertan al sistema educativo o, por lo menos, a quienes nos dedicamos profesionalmente a este campo. Iniciaremos este camino de vuelta a la educación, mostrando lo que consideramos tendencias amplias, generales, para pasar luego a señalar, con una estructura lo más lógica posible, tensiones o tendencias más concretas, más singulares. 
Lo primero que interesa indicar, dado que nos encontramos en el ámbito pedagógico, es que en la sociedad y en las escuelas se está manifestando la tendencia creciente de una gran pluralidad de valores, opiniones, ideas, estilos de vida, etc. Conviene evitar el error de creer que, dado que no compartimos, a lo mejor, algunos de los valores de la posmodernidad, los fines o valores están en crisis. No, no hay crisis de valores en el sentido de ausencia de los mismos. Lo que hay es exceso, mezcla, mixtura. No hay tampoco crisis de valores en el sentido de ausencia de orientación. Los valores, de suyo, son orientativos y normativos. Lo que hay es exceso de direcciones, de fines, de caminos, de orientaciones, de posibilidades, de opiniones. Tal vez tenga razón Marquard cuando señala que:

la experiencia moderna y actual de la pérdida de sentido es la consecuencia de un exceso de pretensiones en relación al sentido; así pues, nuestra dificultad primaria no es la pérdida de sentido, sino el exceso de pretensión de sentido; y lo que nos saca adelante no es el gran lamento por la pérdida de sentido, sino una moderación (una reducción) de la pretensión excesiva de sentido: una dieta de sentido mediante una dietética de la expectativa de sentido (Marquard, 2000, 57-58).

Esta tendencia es un elemento interpretativo clave, como hemos visto, en el análisis filosófico de la crisis del sujeto, y lo es también para comprender, pedagógicamente, otras tensiones educativas y escolares.

La pluralidad de valores y de estilos de vida establece un singular marco interpretativo sobre el horizonte pedagógico. La vivencia de múltiples opciones provoca que se acentúen más los contextos y las situaciones de afirmación que los contextos de verdad, que se fomente más el gusto por la discusión y el debate - necesitamos que alguien nos escuche- que por la reflexión silenciosa y a solas. Lo que interesa es hacerse con una opinión cuanto antes entre todas las que ofrece el mercado, tener una narrativa más o menos definida. Cuando nos encontramos ante muchos caminos y además todos ellos son considerados válidos, la situación ya no se reduce a elegir el mejor, el más verdadero, sino simplemente a elegir y a sentirse afirmativamente realizado en la opción tomada.

Se puede producir así en las situaciones pedagógicas la tendencia, a nuestro juicio, ya presente y que consiste en una peculiar sobrevaloración educativa de la autonomía de la razón de nuestros alumnos. Para nosotros los análisis filosóficos de la razón fragmentada, de la ruptura universalista de la verdad, del relativismo, etc., tiene su máxima expresión educativa en esa preeminencia constructivista de las opiniones de los alumnos. Es lógico que sea así. Como hemos visto, cuando la razón rompe su vinculación con un Todo explicativo, con la posibilidad de alcanzar alguna certeza y se identifica la búsqueda del mejor argumento con el pluralismo de opiniones, la razón automáticamente se atomiza y se "autonomiza". Como nos recuerda Magris,

la escuela está al servicio de los estudiantes cuando los libra de condicionamientos económicos y sociales y ofrece a todos ellos las mismas posibilidades de desarrollar 
su personalidad, cuando los respeta sin mimarles ni adularles y les enseña a no decir envanecidamente su opinión, sino a observar y conocer la realidad con esa atención al objeto que constituye la auténtica independencia intelectual, la capacidad de ver y conocer, muy distinta del presuntuoso hablar ex cátedra (Magris, 2001, 316) ${ }^{11}$.

Esta tendencia puede provocar, a su vez, dos implicaciones negativas para los valores del desarrollo personal que trata de promover la pedagogía. Por un lado, la sobrevaloración de esa autonomía de la razón favorece la actitud de considerar irrelevante el aprendizaje acumulativo de información. Los aprendizajes curriculares tienden a disminuir porque no se trata de llenar cabezas sino de formar un juicio. Por otra parte, al situar como preferente la construcción y posesión de opiniones sobre los más diversos temas disminuye la atención educativa que se debería prestar a la acción. En el discurso pedagógico hemos invertido los órdenes de importancia: nos interesa más conseguir que los alumnos elaboren una opinión a que muevan sus acciones y comportamientos en una dirección u otra. Hay así en las escuelas demasiadas palabras y demasiados discursos y poca, muy poca acción. Los niños y los jóvenes escuchan muchos discursos y se les pide también que reflexionen, pero tienen poco espacio para obrar, para actuar, para reflexionar sobre sus propios actos, para ser agentes de sí mismos y de su vida, para cuestionarse el valor humanizador de sus propias acciones, de su yo y de su vida ${ }^{12}$.

Se oye comentar a los profesores, sobre todo, de universidad que los alumnos llegan con una escasa capacidad de abstracción y con una creciente pereza para pensar. Probablemente, no sea una cosa ni la otra: lo que se está manifestando es una escasa capacidad para pensar lo que otros han pensado. Da casi vergüenza entre el profesorado manifestar que piden a sus alumnos que digan, no lo que piensan ellos o ellas, sus opiniones, sino que expliquen el pensamiento de otro

11. Este mismo escritor nos cuenta que "( $\mathrm{m})$ is compañeros y yo le estamos muy agradecidos a un profesor que, cuando alguno de nosotros, con la inevitable presunción de la adolescencia, empezaba a responder a su pregunta diciendo "yo pienso que...", nos interrumpía mandándonos no pensar nunca y aprender hechos, nombres y fechas. Ya entonces - gracias a él, no a nosotros-comprendíamos que era un modo acertado de enseñar a pensar" (Magris, 2001, 316-317). No comparto en modo alguno esta valoración de una escuela esencialmente memorística, autoritaria y creadora de silencios, pero también es verdad que parece necesario equilibrar ciertas cuestiones escolares que, surgidas con muy buena voluntad y mejor propósito educativo, nadie lo niega, se han desvirtuado exageradamente. Sobre todo, cuando no insistimos lo suficiente en la necesidad de un «[...] profesorado maduro y comprometido ética y afectivamente con todos los alumnos, pero en especial con los cultulral y socialmente más desfavorecidos” (Jordán, 2000, 81).

12. No podemos extendernos ahora en las implicaciones de esta idea, si bien son numerosas y, creemos, que relevantes para entender la educación, en especial, las dificultades actuales de la educación. Uno de los problemas de la escuela, es que, como se ha dicho, hablamos mucho - sobre todo los profesores-y actuamos poco. Pero hay otro menos evidente por estar más extendido, y es la convicción pedagógica de demorar la acción hasta que no se ha teorizado sobre la misma y, por lo mismo, la costumbre de vincular la realización de acciones a su previa construcción de sentidos y explicaciones. 
autor, de tal escritor, etc. Lo pedagógico hoy es que los alumnos tengan su propia opinión, lo que por cierto, es la base futura para alimentar la imparable charlatanería social generada por los mass media.

Pensar que la razón descansa, en su ulterior sentido, en las opiniones que cada uno construye sobre los más diversos temas que quepa imaginar tiende a provocar, en los educadores y en los pedagogos, una intencionalidad muy discursiva y bermenéutica, una especie de docencia periodística que arroja, en clave axiológica, las posibilidades interpretativas de las valoraciones de los diferentes grupos sociales para que los alumnos se decanten, discutan, escuchen, elijan o voten. Así, si hay que considerar los problemas que tiene la población de la tercera edad se emprenden debates, a veces muy sesudos, preparados, documentados, en ocasiones, con conferencias de especialistas y, sin embargo, en raras ocasiones se organizan visitas, por ejemplo, a una residencia de ancianos o a un hospital. Pero aún hay más: la crisis de la razón provocará y contagiará otras crisis cuando observamos que, desde el mundo educativo, se sustrae la pregunta existencial por excelencia: y tú ¿qué haces? Y tú ¿qué haces por tus abuelos y los enfermos?... (Gil, 2000).

No debemos confundirnos en nuestras direcciones educativas. Como nos recuerda Mélich, "(la) discusión es esencial en toda verdadera transmisión (o si se quiere, en toda transmisión educativa). Porque toda transmisión educativa se caracteriza por la capacidad creativa que tiene aquel que la recibe. Si el alumno es simplemente un receptor, si no disidente, si no se enfrenta a lo recibido, la transmisión educativa no es posible [...] Ahora bien, ¿es todo aprendizaje legítimo? O dicho de otro modo, ¿hay límites en la interpretación? La ética es precisamente el límite de la interpretación. O si se prefiere el otro" (Mèlich, 2001, 78; cursivas del original). Odo Marquard considera, por otra parte, que

(q)uien (tal como sucede al ser humano, cuyas experiencias envejecen cada vez más rápidamente y cuyas nuevas experiencias ya no suelen ser experiencias propias) ya no hace sus experiencias, tiene que cultivar la sustitución de la experiencia. Esa cultura de la sustitución de la experiencia (de la adquisición de experiencia descargada de experiencia y alejada de la experiencia) en la que se piensa hoy cuando se habla de "aprender" es la escuela [...] (Marquard, 2000, 97; cursiva añadida).

Con la crisis de la idea de sujeto, la realidad pierde su significado tradicional, sus contornos precisos y estables, y se abren así las puertas, como hemos visto, a multitud de significados posibles, interpretaciones, discursos, valores, etc. La razón, también lo hemos dicho, queda fragmentada, atomizada, anclada en lo cotidiano, en lo débil, en lo singular, en las historias particulares. Pues bien, volvemos a recordar estos indicadores para mostrar su conexión lógica con otra tendencia - esta vez especialmente tensa - en el campo pedagógico y que, a nuestro juicio, tal vez, hemos estado analizando erróneamente, aunque como se verá nos ha permitido a los educadores en general creernos muy importantes, casi imprescindibles, lo que no está nada mal en alguna ocasión. 
Cuando se señala que a la escuela y a los profesores se les está asignando responsabilidades educativas interminables, piénsese, no tanto, como es habitual, en que crece la confianza sobre la educación, sino en que lo escolar, el objeto cultural de lo educativo-institucional, se ha quedado sin fronteras, ha perdido la capacidad de mantener la significación precisa de su valor: la escuela es hoy un "significante flotante", no a la deriva, sino impreciso, que circula en un vacío sin estabilidad ni sentido de ancla.

Ya indicamos que tal vez esta idea pueda parecer atrevida. Pero si se piensa con cierto detenimiento y si, sobre todo, se conoce con cierta profundidad el alcance social de la propuesta filosófica deconstruccionista, se hace bastante evidente que el incremento de demandas hacia la educación es un proceso que también se está dando, pongamos por caso, en la política, en la democracia, en el ámbito de la salud, etc., y que también en todos estos casos, pero sobre todo en la educación, esas demandas no se desarrollan en paralelo con una confianza creciente en la educación ni en sus profesionales. ¿Cómo es posible que suceda esto? ¿Cómo puede explicarse que se proyecten tantas expectativas en la escuela y se desconfíe, al mismo tiempo, de la labor de los profesores?

La constante demanda de que la escuela se ocupe de nuevas finalidades educativas responde perfectamente al esquema deconstruccionista de los significados de las instituciones sociales. Cuestionados y hasta suprimidos los significados precisos de lo que nos rodea y, por tanto, alterado el orden tradicional entre lo principal y lo secundario, los discursos interpretativos se multiplican exponencialmente y, al mismo tiempo, no son asumidos responsablemente por nada ni por nadie. Bien nos valdrían muchos ejemplos para mostrar esta idea. Pero baste considerar ahora el papel que, en algunos casos, están adoptando los padres ante la escuela $y$, en especial, frente a los profesores. Estos padres limitan con frecuencia su participación en el proyecto educativo del centro entrometiéndose literalmente en los aspectos más profesionales, criticando los métodos de enseñanza o hasta las secuencias curriculares. Participan, pues, en ese incremento exponencial de los discursos interpretativos (dando consejos, opiniones, exigiendo, y hasta regañando) pero, al mismo tiempo, deconstruyen la especificidad de sus funciones, obligaciones y responsabilidades directas como padres hacia sus hijos, esto es, renuncian o se alejan de la autoría responsable sobre sus acciones singulares. Como ha señalado Asensio, "[...] no resulta infrecuente constatar que muchas de las críticas dirigidas a los docentes involucran a quienes las formulan, porque la tarea de educar compete al conjunto de la sociedad y no únicamente a unas determinadas personas o instituciones" (Asensio, 2000, 32; cursiva del original).

En el esquema deconstruccionista de los significados de las instituciones sociales, el lenguaje, el discurso, la opinión, saltan la autoría de la acción y hasta la toma de conciencia de las propias acciones realizables para quedarse sólo en los discursos. Cada cual, sujeto o institución, echa siempre los balones fuera, deconstruye la singularidad de sus funciones y se pone a mirar en otra dirección. La educación, no cabe duda, es uno de los referentes lingüísticos, sociales e institucionales donde 
mejor se manifiesta un enorme anonimato, una carencia de autoría responsable y directa que más puede favorecer el que se le arrojen, interminablemente, demandas constantes de nuevas educaciones, fines, métodos, etc.

La escuela recibe, por tanto, muchas demandas porque la educación, como proyecto de desarrollo personal, ha perdido también su significado estable, su correspondencia con unas actividades determinadas, claramente conocidas e identificadas. ¿Sabríamos contestar hoy sin titubear qué es un sujeto educado? ¿Sabríamos responder con claridad quién educa? Las escuelas están hoy sin puertas al campo porque se ha dado un proceso de deconstrucción del sentido de la educación. Pero aún hay más: derrumbadas las fronteras de lo educativo, la educación tiende a ser identificada con la vida, con la pura vida. De este modo, pensamos que la crisis del sujeto ha traído consigo una sobrevaloración de la educación informal y, por tanto, una cierta desacreditación de las propuestas pedagógicas sistematizadas y, en general, de lo que se ha dado en llamar la crisis de las funciones mediadoras, la crisis de las transmisiones.

Se cierra así un círculo explicativo que iniciamos en este apartado con la propuesta de que hay una sobrevaloración de las opiniones y de la razón de los alumnos. En efecto, para que este rasgo pueda darse sin graves contradicciones dentro de la educación, tiene que ir acompañado precisamente de la preeminencia de la educación informal: sólo cuando la educación se identifica con la vida, al perder los perfiles de su significado más restringido, podemos adoptar los adultos una posición de confianza en las capacidades autodidácticas de nuestros alumnos dado que todos pueden aprender a vivir, a tener una narrativa, a vivir acontecimientos relatables, etc.

Si esta tensión ya trae consigo elevados niveles de crisis en la pedagogía, todavía nos queda por mostrar otra tendencia con enormes repercusiones para los profesionales de la educación. En la medida que la educación se identifica con la vida, la pedagogía como saber institucional de fundamentación de transmisiones formativas tiende a desacreditarse o a desaparecer dado que se ha arrancado de raíz sus posibilidades normativas. La educación al perder el contorno preciso de su significado e identificarse con el puro vivir, queda tan absolutamente singularizada en cada sujeto, en cada estilo de vida, en cada forma de ser, en cada narrativa que la pedagogía se hace más innecesaria que nunca. Cuando la educación pasa a constituirse en un significado flotante, la pedagogía, a su vez, tiende a perder su orientación normativa. Prueba de ello es que los movimientos pedagógicos más desarrollados de los últimos años apuestan por un conjunto de claves interpretativas no normativas y totalmente individualistas y personales, más vinculadas a la vida que al sentido tradicional de una instrucción educativa. Así, los discursos centrados en favorecer la identidad de nuestros alumnos, la pedagogía narrativa, las metodologías autobiográficas, etcétera, se encuentran dentro de un nuevo movimiento educativo que dificulta conceptualmente toda propuesta normativa. Como mucho valen para orientar la propia vida e incluso la reflexión existencial de los educadores pero poco dicen acerca de cómo enseñar un currículo concreto 
a un grupo concreto en un contexto concreto. Buena parte de la investigación pedagógica se ha visto empujada a construirse desde y para la educación informal, contribuyendo más aún si cabe a la perdida de fronteras de lo genuinamente educativo: todo educa, el medio ambiente, el estado de bienestar, la vida, las nuevas tecnologías de la información, etc. Todo educa porque, así se piensa, la educación es vivir. Todo educa del mismo modo... y nadie se atreve a afirmar qué criterios o discursos pedagógicos se imponen rotundamente y con fundamento a otros...

\section{CONCLUSIONES}

¿Qué podemos hacer ante este panorama? Ser pedagogo hoy no debería consistir en convertirse, aprovechando los aires posmodernos, en uno más de esos transgresores innovadores incapaces de proponer un rumbo. De ésos nos sobran. Ser pedagogo hoy es asumir la voz paciente y serena del viejo de la tribu para resistirse y para recordar lo esencial entre tanta dirección secundaria. Es atreverse a decir no y no, a no claudicar ante tanta palabrería, ante tanto "significado flotante", ante tanta autocomplacencia, a recordar el valor, el significado del valor de ciertas actividades por encima de otras ${ }^{13}$.

La escuela tiene que convertirse así, desde la perspectiva de una pedagogía de la resistencia creativa, en un espacio y un tiempo privilegiado para la promoción de los valores del desarrollo personal. La escuela tiene que concebirse permanentemente en crisis frente a la pluralidad contradictoria de los valores sociales y frente a la insuficiencia de las disposiciones legales. A un educador nunca le sirve esconderse y protegerse en la legislación educativa porque ésta marca las reglas institucionales mientras que al profesor le ha de iluminar la búsqueda del bien del alumno. Que la escuela esté en crisis significa que tiene que saber identificar en cada momento las diferentes tensiones y contradicciones que genera la convivencia social y las demandas de los padres y de las instituciones, y que esa identificación ha de llevarse a revalorizar las direcciones y los valores que resalten la condición de agente del alumno. Como afirma Bárcena, "(1)a educación, por tanto, depende de la cultura, entendida como texto que se da a leer y que se nos propone como algo que nos da a pensar, para inquietarnos y abrir nuestro borizonte de experiencias" (Bárcena, 2001, 28; cursiva añadida). Habrá ocasiones en que la escuela y el conocimiento pedagógico entren en crisis por su incapacidad para adaptarse a unas acertadas demandas sociales. Pero hay otra posibilidad, en la que

13. Bien nos valdrían las conocidas palabras de Camus: "Dado que ya no vivimos tiempos revolucionarios, aprendamos, al menos, a vivir el tiempo de los rebeldes. Saber decir no. Esforzarse cada uno desde su puesto en crear los valores vitales de los que ninguna renovación podrá prescindir. Mantener lo que vale. Preparar lo que merece vivirse y practicar la felicidad para que se dulcifique el terrible sabor de justicia, son motivos de renovación y esperanza". 
actualmente nos encontramos, por la que el saber pedagógico y la escuela deben tener la responsabilidad de utilizar todos los medios a su alcance para cuestionar críticamente ciertas tendencias dominantes porque alteran, de un modo o de otro, las mejores posibilidades educativas de las personas. La escuela tiene que hacer sus "deberes pedagógicos" (Reyero, 2001, 116; cursiva del original). Éste es el papel principal de una pedagogía de la resistencia creativa frente a la crisis de la idea de sujeto: generar un discurso que sepa contrarrestar las modas y opiniones que dificultan en la actualidad el desarrollo personal de los sujetos. Como afirma Jover "(e)l derecho a la educación se refiere [...] a una persona situada en un contexto pero también a un sujeto con la capacidad de distanciarse de y a partir de los marcos culturales" (Jover, 2000, 221).

Si la escuela es un recinto de resistencia su quid institucional radica en poner en crisis los diferentes discursos educativos para resaltar los que, a su vez, acentúen la capacidad de aprendizaje y el deseo formativo de sus alumnos. La escuela ha sido moderna y será posmoderna y lo que en cada época toque. Pero la escuela, de suyo, tiene ya una referencia estable de juicio pedagógico para reconducir las prácticas y los valores dominantes en la finalidad principal y permanente de capacitar a los sujetos a que se eleven a su condición señorial de su propia vida. Esto no debería contemplarse como una propuesta innovadora. Sí lo es que ha llegado el momento de asumir que dicho propósito hay que perseguirlo y lograrlo, en ocasiones, a pesar... de los padres, la sociedad y los medios de comunicación.

El educador comprometido realmente con el desarrollo de sus alumnos es un profesional cuya máxima preocupación estriba en ir acercando a sus alumnos, según criterios fundamentados de carácter didáctico y psicológico, a la vivencia de experiencias del disenso ante lo convencionalmente admitido. El pedagogo es así un agitador de conciencias, sobre todo, de las que tienden a autocomplacerse con un estado de cosas. El pedagogo debe ayudar a los docentes a lograr en sus alumnos, por lo menos, "(e)l reconocimiento de que debo estar dispuesto a dejar valer en mí algo contra mí, aunque no haya ningún otro que lo vaya a hacer valer contra mí (Gadamer, 1977, 438). Pero aún hay más, todavía la función educadora puede dar un paso más. Como dicen García Carrasco y García del Dujo,

(e)l interés del pedagogo por el sujeto se centra en aportar contenidos de conciencia y en favorecer el posicionamiento del sujeto respecto a esos contenidos; en última instancia, la ontología de los procesos educacionales viene dada por el sistema de sucesos en la subjetividad y la Pedagogía queda constituida por el sistema de acciones que pretenden favorecer acontecimientos en la subjetividad (García Carrasco y García del Dujo, 2001, 62; cursiva añadida).

No se trata sólo de analizar curricularmente los temas controvertidos de las sociedades, los que están ya ahí y la escuela recibe, no se trata tampoco sólo de incentivar el juicio para verter en controvertido lo comúnmente admitido. Se trata sobre todo de incentivar en los alumnos y alumnas otras posibilidades de poderser. Aquí esta la raíz y el alcance más educativo de una pedagogía de la resistencia 
creativa: mostrar al alumno su yo aún no realizado, su horizonte posible de despliegue humanizador, las irrealidades de su subjetividad, desde lo que sabemos hoy del hombre y para comprometerse en acciones moralmente valiosas. 


\section{BIBLIOGRAFÍA}

AGAMBEN, G. (1998) El bombre sin contenido. Barcelona, Arlea.

ALTAREJOS, F. (1999) Dimensión ética de la educación. Pamplona, Eunsa.

ARENDT, H. (1993) La condición bumana. Barcelona, Paidós.

ASENSIO, J. M. (2000) La formación del docente en y para la complejidad, Teoría de la Educación. Revista Interuniversitaria, 12, 29-43.

ASENSIO, J. M.å; BÁRCENA, F. y MĖLICH, J. C. (2001) Educación, vida humana y biopoder, en VAZQUEZ, G. (ed.) Educación y calidad de vida. Madrid, Editorial Complutense, 81-115.

BÁRCENA, F. (2001) La esfinge muda. El aprendizaje del dolor después de Auschwitz. Barcelona, Anthropos.

BÁRCENA, F. y MĖLICH, J. C. (1999) La educación como acontecimiento ético. Natalidad, narración y bospitalidad. Barcelona, Paidós.

BÜRGER, CH. y BÜRGER, P. (2001) La desaparición del sujeto. Una historia de la subjetividad de Montaigne a Blanchot. Madrid, Akal.

CASSEY, K. (1995-1996) The new narrative research in education, Review of Research in Education, 21, 211-253.

CRESPI, F. (1996) Aprender a existir. Madrid, Alianza.

CRUZ, M. (comp.) (1996) Tiempo de subjetividad. Barcelona, Paidós.

DELACAMPAGNE, C. (1999) Historia de la filosofia en el siglo XX. Barcelona, Península.

DERRIDA, J. (1994) Mârgenes de la Filosofía. Madrid, Cátedra.

DUCH, Ll. (1997) La educación y la crisis de la modernidad. Barcelona, Paidós.

- (1998) Mito, interpretación y cultura. Barcelona, Herder.

ESCÁMEZ, J. y GIL, R. (2001) La educación en la responsabilidad. Barcelona, Paidós.

FINKIELKRAUT, A. (1998) La bumanidad perdida. Ensayo sobre el siglo XX. Barcelona, Anagrama.

GADAMER, H.-G. (1977) Verdad y método. Salamanca, Sígueme.

GARCÍA CARRASCO, J. y GARCÍA DEL DUJO, A. (2001) Teoría de la educación II. Salamanca, Ediciones Universidad de Salamanca.

GERGEN, K. J. (1996) Realidades y relaciones: aproximaciones a la construcción social. Barcelona, Paidós.

GIDDENS, A. (1998) Modernidad e identidad del yo. Barcelona, Península.

GIL CANTERO, F. (2000) Educación, identidad y narración, en XIX Seminario Interuniversitario de Teoría de la Educación "Educación y Calidad de Vida". San Lorenzo de El Escorial, noviembre de 2000 (www.ucm.es/info/site).

IBÁÑEZ-MARTÍN, J. A. (2001) El profesorado de Universidad del tercer Milenio. El nuevo horizonte de sus funciones y responsabilidades, Revista Española de Pedagogia, 59 (220), 441-466.

JIMÉNEZ, J. (1989) La vida como azar. Madrid, Mondadori.

JONATHAN, R. (1992) Educación, Filosofía de la Educación y contexto, en AA.VV. La Filosofía de la Educación en Europa. Madrid, Dykinson, 281-299.

JORDÁN, J. A. (2000) Influencia del profesorado en la integración escolar del alumnado minoritario, Teoría de la Educación. Revista Interuniversitaria, 12, 67-83.

JOVER, G. (2001) What does the right to education mean? A look at an international debate from legal, ethical, and pedagogical points of view, Studies in Pbilosophy and Education, 20 (3), 213-223.

JOVER, G.; CASARES, P.; GIL, F. y PAYÁ, M. (2001) La crisis de la sociedad actual, en ORTEGA, P. (coord.). Conflicto, Violencia y Educación. Murcia, Cajamurcia Obra Social y Cultural, 23-75. 
LARROSA, J. (1996) Narrativa, identidad y desidentificación, en La experiencia de la lectura. Estudios sobre literatura y formación. Barcelona, Laertes, 461-482.

LEVI, P. (1998) Si esto es un hombre. Barcelona, Muchnik.

LEVINAS, E. (1977) Totalidad e infinito. Ensayo sobre la exterioridad. Salamanca, Sígueme. MAcINTYRE, A. (1987) Tras la virtud. Barcelona, Crítica.

MAGRIS, Cl. (2001) Utopia y desencanto. Historias, esperanzas e ilusiones de la modernidad. Barcelona, Anagrama.

MARQUARD, O. (2000) Apología de lo contingente. Estudios filosóficos. Valencia, Instituto Alfons el Magnànim.

MÈLICH, J.-C. (2001) La ausencia del testimonio. Ética y pedagogía en los relatos del Holocausto. Barcelona, Anthropos.

MUGUERZA, J. y CEREZO, P. (eds.) (2000) La filosofía boy. Barcelona, Crítica.

ORTEGA, P. y MÍNGUEZ, R. (2001) La educación moral del ciudadano de boy. Barcelona, Paidós.

PEREDA, C. (1998) Sueños de vagabundos. Un ensayo sobre filosofia, moral y literatura. Madrid, Visor.

PINILLOS, J. L. (1997) El corazón del laberinto. Madrid, Espasa-Calpe.

REYERO, D. (2001) El valor educativo de las identidades colectivas: cultura y nación en la formación del individuo, Revista española de Pedagogía, 59 (218), 105-120.

RICOEUR, P. (1996a) Si mismo como otro. Madrid, Siglo XXI.

- (1996b) Tiempo y narración. Tomo III: el tiempo narrado. Madrid, Siglo XXI.

- (1997) Retórica, poética y hermenéutica, en Horizontes del relato. Lecturas y conversaciones con Paul Ricoeur. Madrid, UAM.

- (1999) Historia y narratividad. Barcelona, Paidós-ICE de la Universidad de Barcelona.

- (2001) Ensayos de bermenéutica II. Del Texto a la acción. Buenos Aires, FCE.

RORTY, R. (1996) Objetivismo, relativismo y verdad. Escritos filosóficos, 1. Barcelona, Paidós.

SÁBADA, J. (1989) Ética analítica, en CAMPS, V. (ed.). Historia de la ética. Tomo III: La ética contemporánea. Barcelona, Crítica, 162-220.

SALINAS, H. (1998) Individuo, cultura y crisis. Bilbao, Desclée de Brouwer.

STEINER, G. (1989) Presencias reales. ¿Hay algo en lo que decimos? Barcelona, Destino.

- (1990) Lenguaje y silencio. Ensayos sobre la literatura, el lenguaje y lo inbumano. Barcelona, Gedisa.

TAYLOR, Ch. (1994) La ética de la autenticidad. Barcelona, Paidós-ICE de la Universidad Autónoma de Barcelona.

- (1996) Fuentes del yo. La construcción de la identidad moderna. Barcelona, Paidós.

- (1997) Argumentos filosóficos. Ensayos sobre el conocimiento, el lenguaje y la modernidad. Barcelona, Paidós.

TERRÉN, E. (1999) Educación y modernidad. Entre la utopia y la burocracia. Barcelona, Anthropos.

TRILLA, J.; AYUSTE, A.; ROMAÑÁ, T. y SALINAS, H. (2001) Educación y calidad de vida. Las cosas, los otros y uno mismo, en VÁZQUEZ, G. (ed.). Educación y calidad de vida. Madrid, Editorial Complutense, 117-179.

VILLACAÑAS BERLANGA, J. L. (2000) La metafísica, crisis y reconstrucciones, en MUGUERZA, J. y CEREZO, P. (eds.). La filosofía boy. Barcelona, Crítica, 355-373.

ZAMBRANO, M. (1989) Delirio y destino. Madrid, Mondadori. 